Былинская Наталья кандидат психологических наук, доцент, заведующая кафедрой психологии

Брестского государственного университета им. А.С. Пушкина, г. Брест (Республика Беларусь) http://orcid.org:0000-0002-2545-5592 DOI https://doi.org/10.35619/praprv.v1i15.181

\title{
ОБЫДЕННЫЕ ПРЕДСТАВЛЕНИЯ О ЛЮБВИ ЖЕНЩИН И МУЖЧИН ПОЖИЛОГО ВОЗРАСТА
}

Аннотация. В статье излагаются результаты исследования представлений о любви, существуюших в сознании пожильх людей. Известно, что представления людей о любви формируются на основе обыденного житейского опыта, обретенного в процессе сочиального взаимодействия. В научной литературе представлень описания разньх типов любви: любовь матери к ребенку, любовь к Богу, эротическая любовь, братская любовь, любовь-симпатия и дружба, любовь-привязанность, любовь-долг, любовь к самому себе и пр. Изучение структуры и содержания обыденных представлений о любви позволило зафиксировать их специфику у женщин и мужчин пожилого возраста. В обыденном сознании пожилых женщин присутствует два вида любви: идеальная любовь, в которой присутствуют счастье, доверие, смысл жизни, и любовь-дружба. Мужчинь пожилого возраста ассоциируют любовь с чувственными отношениями между мужчиной $u$ женщиной. Они называют любовь двигателем мира, славным, великим, нежным чувством, переживание которого может быть болезненным и требовать самоотречения.

Среди многообразия типов любви, описанных в научной литературе, в обыденном сознании пожильх людей четко дифференщируются только отдельные ее виды. Женщинами любовь идеализируется и ассоииируется либо с дружбой, либо с верой во Всевышнего, мужчинами же любовь воспринимается как отношение полов.

Ключевые слова: любовь, симпатия, дружба, обыденные представления, метод свободного описания, факторный анализ, фактор, категория, конструкт.

Постановка проблемы. Феномен любви с давних времен интересовал как простых людей, так и представителей разных наук: философии, физиологии, социологии, психологии. Однако до сих пор феномен любви отличается отсутствием единого определения и общепризнанной научной теории. По мнению исследователей в области социальной психологии (Бо Ли, Ф. Рассел, М. Тапиа и др.), чувство любви находится на стыке двух составляющих: физического тела, являющегося источником сексуальных импульсов, и социального компонента, гаранта института супружества (Горский, 1990; Розин, 1991; Московичи, 2007). Однако такое понимание любви является однобоким, будучи сосредоточенным только лишь на эротическом взаимообмене или на браке.

Существующие в науке концепции и типологии любви носят описательный характер, отражая либо чувственные отношения партнеров, либо симпатию и дружбу. При этом часто понимание авторами любви опосредовано их субъективными, житейскими представлениями. Безусловно, любовь проникнута обыденной психологией, откуда люди черпают ожидания и представления о данном феномене. Научные и обыденные представления трансформируются друг в друга, отражая специфику исторических эпох и разное отношение представителей этих эпох к пониманию феномена любви. Описание особенностей культурно-исторической трансформации представлений о любви легко можно обнаружить в научно-популярной, художественной, философской, исторической литературе, где любовь ассоциируется и с продолжением рода, и с сексуальным влечением, и с преданностью и верностью партнеру (вечная любовь), и с поиском смысла жизни, и с самоактуализацией личности, и с Богом и прочее (Московичи, 2007; Братусь, 2009; Рубин, 1987; Фромм, 2008). По мнению Г. Крайг, 
степень удовлетворенностью жизнью, ощущение гармонии, благополучия и эмоционального комфорта определяется в социальном контексте семьи и личных отношениях человека, связанных, в том числе, с переживанием любви (Крайг, 2000). Однако понимание любви современными людьми, жизнь которых характеризуется быстрым темпом ее протекания, информационной насыщенностью, нехваткой времени, изменением ценностей и др., наверняка отличается от понимания любви, существовавшего у представителей предыдущих эпох.

Анализ исследований по проблеме. В психологической литературе нами зафиксированы исследования представлений о любви, существующие у людей разного пола в периоды юношества, ранней и средней взрослости. Результаты этих исследований показали, что любовь на данных этапах жизни ассоциируется с сексом, партнером противоположного пола, с ребенком, близостью, дружбой, взаимностью, доверием, страстью, романтикой, страданием, обязанностями и долгом (Московичи, 2007; Рубин, 1987; Гозман, 1987; Розенова, 2006). Особый интерес, на наш взгляд, вызывает содержание представлений о любви у людей пожилого возраста. С одной стороны, в период поздней взрослости в организме происходят интенсивные физиологические изменения, связанные с естественными процессами старения, с другой - имеют место изменения в семейных и личных отношениях, связанные, например, с выходом на пенсию, прекращением воспитательной функции, появлением большего количества свободного времени и пр. Современный мир делает пожилых людей более мобильными, активными, стремящимися к достижениям и саморазвитию. И если сто лет назад человек в возрасте примерно шестидесяти лет, когда доживал до него, считался дряхлым стариком, то в настоящее время среди обычных людей бытует мнение, что это возраст еще «цветущего», полного сил человека.

Необходимо отметить, что еще совсем недавно существовало табу на отношения между мужчиной и женщиной в период поздней взрослости. Любовь пожилых людей вызывала негативное отношение, осуждение и порицание социума. Однако, современные тенденции развития отношений обоих полов свидетельствуют о том, что чувство любви может переживаться людьми в любом возрасте.

Цель настоящего исследования заключалась в изучении структуры и содержания обыденных представлений о любви женщин и мужчин пожилого возраста.

Изложение основного материала исследования. Методологической основой эмпирического исследования выступил когнитивный подход в понимании обыденных представлений как иерархически организованной системы коррелирующих между собой шкал-характеристик или качеств (Петренко, 2005; Шмелев, 1983). Для изучения структуры и содержания обыденных представлений в настоящем исследовании использовался метод свободного описания, результаты которого затем обрабатывались с помощью факторного анализа. Метод свободного описания дает возможность выявить содержание сознания респондентов без привнесения исследователем собственных установок на понимание изучаемой области действительности. Факторный анализ является математической процедурой, позволяющей выявить скрытые от непосредственного анализа взаимосвязи между отдельными характеристиками. Итогом факторного анализа выступают «пучки» или «связки» характеристик, образующих фактор. То содержание, которое с точки зрения математики, образует фактор, на психологическом уровне означает категорию или конструкт (или объединение качеств), образующих структуру представлений. Разные качества вносят разный вклад в образование категории. Цифры, стоящие возле каждого качества, означают его нагрузку: чем больше их значение, тем более вес определенного качества в образовании фактора. Кроме иерархии качеств, образующих категорию, факторный анализ позволяет определить также ее субъективную значимость, выраженную в процентах общей дисперсии.

В исследовании принимали участие женщины $(n=50)$ и мужчины $(n=47)$ в возрасте от 60 лет и старше. Участникам исследования предлагалось написать сочинение: «Что в Вашем понимании есть любовь?» 
Представления о любви женщин образованы следующими независимыми (ортогональными) факторами-категориями.

Первый фактор (общая дисперсия 9,2\%) - «Любовь к Богу», образован шкалами: Бог $(0,913)$, счастье $(0,849)$, смысл жизни $(0,691)$. Это говорит о том, что для женщин пожилого возраста любовь к Богу является счастьем и смыслом жизни.

Второй фактор (общая дисперсия 8,1\%) - «Самоотречение», образован шкалами: самоотверженность $(0,996)$, самоотречение $(0,996)$, всплеск $(0,996)$. Содержание фактора говорит о том, что в самоотречении заключается смысл спасения от ощущения одиночества и возрастание потребности быть кому-то нужной.

Третий фактор (общая дисперсия 7,4\%) - «Надежда», включает характеристики: надежда $(0,932)$, страсть $(0,824)$, умение $(0,568)$. Данный фактор говорит, о том, что любовь это страсть, с одной стороны, а с другой, умение, приходящее с годами, дающее возможность любить всеми силами.

Четвертый фактор (общая дисперсия 6,8\%) - «Самопожертвование», включает шкалы: взаимопомощь $(0,962)$, желание помогать $(0,962)$, доверие $(0,847)$. В данном конструкте любовь характеризуется желанием помогать близким, доверять и быть доверенным лицом.

Пятый фактор (общая дисперсия 6,2\%) - «Развитие», образован шкалами: развитие $(0,948)$, рост $(0,848)$, жизнь $(0,828)$. Содержание фактора говорит о том, что любовь является источником роста, развития и продолжения жизни. Под развитием можно понимать как личностное развитие, так и продолжение в детях, внуках и правнуках, путем передачи знаний и жизненного опыта.

Шестой фактор (общая дисперсия 5,7\%) - «Дружеское общение», образован шкалами: дружба $(0,988)$, общение $(0,988)$. В данном конструкте, понятие любовь ассоциируется с дружбой и общением. Для женщин этой возрастной категории платонические взаимоотношения преобладают над физиологическими, в связи с чем трансформируется понятие любви, которое опосредуется новыми социальными ролями бабушки, прабабушки, пенсионерки и пр.

Седьмой фактор (общая дисперсия 5,7\%) - «Душевное общение» образован дескрипторами: состояние души $(0,930)$, радость общения $(0,891)$. Любовь респондентами характеризуется как состояние души, возникающим при взаимодействии с другим человеком, с которым приятно и радостно общаться.

Восьмой фактор (общая дисперсия 5,2\%) - «Верность» образован шкалами: верность $(0,910)$, уступчивость $(0,804)$, нежность $(0,552)$. Согласно данному конструкту, любовь - это взаимные отношения, подразумевающие верность, доверие, уважение и стремление уступать партнеру.

Представления о любви мужчин образованы следующими независимыми факторамиконструктами.

Первый фактор (22,5\% общей дисперсии) - «Двигатель мира», содержит шкалы: двигатель мира $(0,994)$, чувство радости $(0,994)$.

Второй фактор $(17,7 \%$ общей дисперсии) - «Ответственность», включает характеристики: ответственность $(0,885)$, взаимопонимание $(0,843)$, нежность $(0,692)$, уважение $(-0,548)$. В содержание этого конструкта включены дескрипторы «взаимопонимание» и «нежность», которые связаны с уважением и ответственностью за любимых.

Третий фактор (15,4\% общей дисперсии) - «Славное чувство», образован шкалами: славное чувство $(0,897)$, доброта $(0,833)$, глубочайшее уважение $(-0,482)$. Содержание этой категории свидетельствует о том, что любовь это славное, доброе чувство. При этом, по мнению респондентов, любовь нельзя приравнивать к уважению, о чем говорит зафиксированная в данном факторе шкала «глубочайшее уважение» с отрицательной нагрузкой. Здесь эти два понятия разводятся, причем сразу в двух категориях.

Четвертый фактор (15\% общей дисперсии) - «Болезнь», содержит шкалы: болезненное состояние $(0,989)$, идеализация $(0,989)$, печаль $(0,981)$. С одной стороны, 
мужчины пожилого возраста сравнивают любовь с болезненным состоянием, с другой стороны, отмечают идеализацию этого чувства. Связь в одном факторе этих двух дескрипторов говорит о том, что в идеале любовь существует, но в плане реальных переживаний этого чувства, по мнению участников исследования, состояние любящего можно сравнить с состоянием болеющего человека.

Пятый фактор (10,7 \% общей дисперсии) можно обозначить как «Самоотречение», поскольку он включает шкалы самоотречение $(0,977)$ и высокое, великое чувство $(0,729)$.

Шестой фактор (8,9\% общей дисперсии) - «Рациональный контроль» содержит один дескриптор с отрицательной нагрузкой: мания $(-0,949)$. Отрицательный знак этой шкалы свидетельствует о том, что, по мнению респондентов, любовь не должна быть сильным увлечением и пристрастием - «не мания». Чувства, связанные с любовью, должны осознаваться и контролироваться человеком.

Для удобства сравнительного анализа выделенные факторы-категории расположены в следующей таблице в порядке убывания их субъективной значимости для респондентов.

Таблий 1.

Обыденные представления о любви мужчин и женщин пожилого возраста

\begin{tabular}{|c|l|c|l|c|}
\hline \multirow{2}{*}{$\begin{array}{c}\text { № } \\
\text { рактора }\end{array}$} & \multicolumn{4}{|l|}{ Показатели основных категорий представлений о любви у представителей } \\
разных полов
\end{tabular}

Таблица 1 наглядно демонстрирует, что обыденные представления женщин пожилого возраста отличаются от таковых у мужчин по содержанию и по количеству образующих конструктов. Любовь в представлениях женщин, структура которых включает восемь независимых факторов, подразумевает душевный комфорт, гармонию, духовность, поиск смысла жизни, нравственность, самопожертвование ради других людей, что согласно заповедям христианства приближает человека к Богу. В обыденном сознании представительниц прекрасного пола присутствует два вида любви, а именно: идеальная любовь, в которой присутствуют счастье, доверие, смысл жизни, и любовь-дружба, где находят место радость общения, нежность, уступчивость, дружба.

Мужчины пожилого возраста ассоциируют любовь с чувственными отношениями между мужчиной и женщиной. Они называют любовь двигателем мира, славным, великим, нежным чувством, переживание которого может быть болезненным и требовать самоотречения. При этом в обыденных представлениях респондентов мужского пола, образованных шестью независимыми факторами, наиболее четко обнаруживается только один вид любви - несчастная любовь, когда наряду с чувством радости, нежностью, взаимопониманием и идеализацией другого, человек ощущает боль, страдание и печаль.

Необходимо отметить, что в научной литературе нами были зафиксированы разные классификации типов любви, среди которых разные ученые-исследователи (Братусь, Московичи, Рубин, Фромм и др.) наиболее часто выделяют любовь матери к ребенку, любовь к Богу, эротическую или страстную любовь, братскую любовь, любовь-симпатию и 
дружбу, любовь-привязанность, любовь-долг, любовь к самому себе и пр. (Московичи, 2007; Братусь, 2009; Рубин, 1987; Фромм, 2008; Розенова, 2006). Однако в настоящем исследовании большинство из перечисленных видов обнаружено не было. Отсутствие в обыденных представлениях участников исследования эротической, романтической и страстной любви объясняется, с одной стороны, возрастными особенностями и связанными с ними физиологическими процессами в организме женщин и мужчин, с другой стороны тем, что большинство респондентов на момент исследования являлись вдовами и вдовцами. Наибольший интерес вызывает факт отсутствия в обыденном сознании пожилых людей любви к самому себе, братской любви, любви-симпатии, привязанности и долга. Возможно, это связано со спецификой представлений мужчин и женщин периода поздней взрослости о самом себе, о партнере, о близких, о семье, о другом человеке вообще.

Выводы из данного исследования. В целом, результаты проведенного исследования показали, что для женщин и мужчин пожилого возраста понятие «любовь» представляет определенную психологическую реальность, опосредованную их конкретным опытом повседневной жизни. Для представителей обоих полов любовь подразумевает качественно различные отношения. Среди многообразия типов любви, описанных в научной литературе, в обыденном сознании респондентов четко дифференцируются только отдельные ее виды. Женщинами любовь идеализируется и ассоциируется либо с дружбой, либо с верой во Всевышнего, мужчинами же любовь воспринимается как отношение полов. Отсутствие в сознании людей пожилого возраста представлений о любви других видов требует проведения дополнительных исследований.

\section{СПИСОК ССЫЛОК}

Братусь, Б. С. (2009). Любовь как психологическая презентация человеческой сущности. Вопросы философии, 12, 30-42.

Гозман, Л. Я. (1987). Психология эмоциональных отношений. Москва: МГУ.

Горский, Д. П. (1990). Философия любви. Москва: Политиздат.

Крайг, Г. (2000). Психология развития. Санкт-Петербург: Питер.

Московичи, С. (2007). Социальная психология. Санкт-Петербург: Питер.

Петренко, В. Ф. (2005). Основы психосемантики. Санкт-Петербург: Питер.

Розенова, М. И. (2006). Опыт психологического исследования представлений о любви на уровне обыденного сознания людей. Мир психологии, 1, 241-254.

Розин, В. М. (1991). Любовь и сексуальность в культуре, семье и взглядах на половое воспитание. Москва: Логос.

Рубин, 3. (1987). Исследования отношений в процессе общения. Москва: Владос.

Фромм, Э. (2008). Искусство любить. Санкт-Петербург: Издательский Дом «Азбукаклассика».

Шмелев, А. Г. (1983). Введение в экспериментальную психосемантику: теоретикометодологические основания и психодиагностические возможности. Москва: МГУ.

\section{REFERENCES}

Bratus. B. S. (2009). Lyubov kak psikhologicheskaya prezentatsiya chelovecheskoy sushchnosti [Love as a psychological representation of the essence of man]. Voprosy filosofii. 12. $30-42$.

Gozman. L. Ya. (1987). Psikhologiya emotsionalnykh otnosheniy. [Psychology of emotional relationships]. Moskva: MGU.

Gorskiy. D. P. (1990). Filosofiya lyubvi. [Philosophy of love]. Moskva: Politizdat.

Krayg. G. (2000). Psikhologiya razvitiya. [Human development]. Sankt-Peterburg: Piter.

Moskovichi. S. (2007). Sotsialnaya psikhologiya. [Social Psychology]. Sankt-Peterburg: Piter.

Petrenko. V. F. (2005). Osnovy psikhosemantiki. [Basic principles of psychosemantics]. Sankt-Peterburg: Piter. 
Rozenova. M. I. (2006). Opyt psikhologicheskogo issledovaniya predstavleniy o lyubvi na urovne obydennogo soznaniya lyudey. [The experience of psychological research of ideas about love at the level of everyday consciousness of people]. Mir psikhologii. 1. 241-254.

Rozin. V. M. (1991). Lyubov $i$ seksualnost $v$ kulture. semye $i$ vzglyadakh na polovoye vospitaniye. [Love and sexuality in culture, family and views on sex education]. Moskva: Logos.

Rubin. Z. (1987). Issledovaniya otnosheniy $v$ protsesse obshcheniya. [Research of relationships in the process of communication]. Moskva: Vlados.

Fromm. E. (2008). Iskusstvo lyubit. [Art of loving]. Sankt-Peterburg: Izdatelskiy Dom «Azbuka-klassika».

Shmelev. A. G. (1983). Vvedeniye v eksperimentalnuyu psikhosemantiku: teoretikometodologicheskiye osnovaniya $i \quad$ psikhodiagnosticheskiye vozmozhnosti. [Introduction to experimental psychosemantics: theoretical and methodological grou nds and psychodiagnostic capabilities]. Moskva: MGU.

\title{
ORDINARY REPRESENTATIONS OF LOVE AMONG ELDERLY WOMEN AND ELDERLY MEN
}

\author{
Candidate of Psychological Sciences, Associate Professor \\ of chair of Psychology of the Brest State \\ University in the name of A.S. Pushkin, \\ Brest, Belarus \\ http://orcid.org /0000-0002-2545-5592 \\ DOI https://doi.org/10.35619/praprv.v1i15.181
}

\begin{abstract}
The article presents the results of researching ideas about love that exist in the minds of older people. It is known that people's ideas about love are formed on the basis of everyday life experience gained in the process of social interaction. In the scientific literature, descriptions of different types of love are presented: love of a mother for a child, love for God, erotic love, brotherly love, love-sympathy and friendship, love-attachment, love-duty, love for oneself, etc. Study of the structure and content of everyday life ideas about love made it possible to fix their specificity in women and men of advanced age. In the everyday consciousness of older women there are two types of love: ideal love, in which there is happiness, trust, the meaning of life, and love-friendship. Older men associate love with a sensual relationship between a man and a woman. They call love the engine of the world, a glorious, great, tender feeling, the experience of which can be painful and require self-denial. Among the variety of types of love described in the scientific literature only certain types of love are clearly differentiated in the ordinary consciousness of older people. Women idealize love and associate either with friendship or with faith in the Almighty, while men perceive love as a gender relationship.

Keywords: love, sympathy, friendship, ordinary representations everyday ideas, the method of free description, factor analysis, factor, category, construct.
\end{abstract}

